Article

\title{
Exploring Manufacturing Process and Degradation Products of Gilt and Painted Leather
}

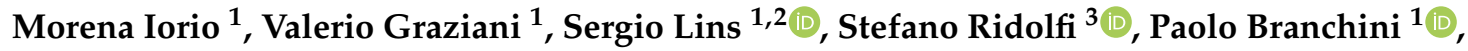 \\ Andrea Fabbri ${ }^{1}$, Gabriel Ingo ${ }^{4}$, Gabriella Di Carlo ${ }^{4}$ and Luca Tortora ${ }^{1,5, *(D)}$ \\ 1 Surface Analysis Laboratory INFN Roma Tre, Via della Vasca Navale 84, 00146 Rome, Italy \\ 2 Sapienza University of Rome, Department of Basic and Applied Sciences for Engineering, \\ Via Antonio Scarpa 14/16, 00161 Rome, Italy \\ 3 Ars Mensurae, Via Vincenzo Comparini 101, 00188 Rome, Italy \\ 4 Institute of Nanostructured Materials-National Research Council, Research Area-Montelibretti, \\ via Salaria km 29.3, 00015 Monterotondo, Italy \\ 5 Department of Sciences, Via della Vasca Navale 84, 00146 Rome, Italy \\ * Correspondence: luca.tortora@uniroma3.it; Tel.: +39-338-541-3448
}

Received: 28 June 2019; Accepted: 22 July 2019; Published: 26 July 2019

\begin{abstract}
In this work, we studied the manufacturing processes and the conservation state of gilt and painted leather fragments from Palazzo Chigi in Ariccia (Italy) by using different analytical techniques. Leather fragments present a silver leaf superimposed onto leather support. A gold varnish and different painted layers decorate it all. A top-down analytical approach was used to investigate this complex multilayer structure, which adopted techniques with different sampling depths. Organic and inorganic constitutive materials together with related degradation products were studied by time of flight secondary ion mass spectrometry (ToF-SIMS), attenuated total reflectance-Fourier transform infrared spectroscopy (ATR-FTIR), and macro X-ray fluorescence (MA-XRF). The findings have revealed the presence of different elements and species as calcium and iron in the leather support, which was attributed to the un-hairing process in the leather tanning. Regarding what concerns the silver leaf, where the varnish cracked, silver chlorides, oxides, and sulfides were detected as degradation products of the silver leaf. Proteinaceous compounds were also identified where the silver leaf is unprotected by the varnish. These ion signals reveal a potential use of animal glue on both sides of the silver leaf to promote durable adhesion. In the gold varnish, the surface analysis revealed organic compounds such as resins and oils. In particular, the copresence of linoleic, arachidonic, and lignoceric acid ion signals in the yellow area suggests the use of aloe as a colorant. Lead ions in the same area were detected and attributed to the use of lead as siccative. Blue areas were obtained by using indigo and lead white in addition to an oil binder. This is confirmed by the detection of indigotin, fatty acid, and lead soap ion signals. A copper-based pigment was used to depict the green areas and copper oxalates were identified as its degradation products. Lastly, no significant information about the red colorant was obtained. Colophony is present as a component of the final varnish.
\end{abstract}

Keywords: leather; MA-XRF; ATR-FTIR; ToF-SIMS; manufacturing process; degradation products

\section{Introduction}

Gilt and painted leather was one of the most luxurious types of wall decoration largely used in high-status public buildings, palaces, stately homes, and high-class mansions. Examples of gilt and painted leather can be found in decorative wall hangings, paintings, and other furnishings. It was used in ecclesiastic settings as altar frontals and ecclesiastical vestments [1]. 
The manufacture of gilt leather begun in North Africa (Ghadames, Libya) and was introduced in Spain during the early Middle Ages. Later, it spreads through Spain toward the rest of Europe [2].

The production of gilt leather consists of a very laborious process. The first step is making the silver leaf adhere to the leather support using animal glue and, subsequently, apply a yellow oil-resin varnish. Recipes stated that the oil-resin varnish forming the golden-like surface on the silver leaf generally consisted of heat-bodied linseed oil with lead components (pigments such as massicot or minium can be used). In addition, resins (such as sandarac, colophony, etc.), fossils (e.g., amber), and organic colorants (such as aloe, asphalt, saffron, dragon blood, etc.) were added [1,3]. Decorative motifs were commonly stamped with woodblocks or by techniques of surface modification such as embossing [4,5]. The last step consisted of applying oil paints and glazes for decorations. Heat-bodied oils or a mixture of oils and resins were used as binding media [1].

The complex overlapping of inorganic and organic materials makes the conservation of this type of artifact very difficult.

Among the others, one of the main problems related to the conservation of leather refers to the decorative surface layers. In particular, special attention is dedicated to the tarnishing of the silver leaf, which leads to aesthetic damage of the leather artifacts. Generally, in this type of material, silver tarnishing is promoted by a large variety of factors, such as the natural aging and degradation of the overlapped oil-resin varnish protecting layers that may embrittle generating micro-cracking [3]. In this way, the exposed silver leaf surface can be subjected to degradation phenomena. It is well known that silver tarnishing usually takes place as a consequence of the reaction between silver and reduced Sulphur-containing compounds such as hydrogen sulphides and carbonyl sulphides present in the air or elemental sulphur. In addition, the prolonged exposure to an environment containing chloride ions-as in coastal areas-or the contact with human skin, could lead to the formation of silver chlorides $[1,6]$.

Furthermore, past conservation treatments with oils and solvents can be responsible for further degradation processes. Calnan, in a previous work, stated that excessive oiling in conservation treatments can lead to the darkening and the delamination of painted surfaces. Moreover, the use of impure oils can lead their fatty acids to migrate to the surface [2].

Mannina et al. [4] refer about a study on gilt and painted leathers of the XVIII century. The leather and its decorations have been studied through the analysis of cross-sections and by several analytical techniques such as XRF spectroscopy, Raman spectroscopy, and Scanning Electron Microscopy to obtain information about the constitutive materials, the technique, and the preservation state.

Ioele et al. [7] investigated the painting technique of different gilt leather with special attention to the indigo pigment. In particular, optical microscopy, XRF, SEM-EDX, micro FT-IR, and micro Raman have been used. The analyses identified the pigment in all the works, providing information about the different painting techniques employed.

In a previous work [8], we studied a gilt and painted leather coming from an altar frontal and dated to the mid-17th century. During the conservation treatment at the Istituto Superiore per la Conservazione ed il Restauro, various scientific analyses were employed (optical microscopy, XRF, SEM-EDX, micro-FTIR, and micro-Raman), which allowed the identification of most constitutive materials. More difficult was the identification of the components of gold varnish. In that work, the authors proposed to study the artifact by time-of-flight secondary ion mass spectrometry (ToF-SIMS) to obtain information about the organic substances.

Recently, in fact, ToF-SIMS is becoming an increasingly used tool for surface analysis and it is particularly useful for different fields of research to investigate inorganic and organic materials, including cultural heritage studies.

Its excellent mass resolution, sensitivity, and high spatial resolution allow obtaining both chemical and distributional (laterally and in-depth) information of a large variety of works of art including gilded metal artifacts $[9,10]$. 
It can be considered a non-destructive technique since it explores only the first atomic layers of the sample. Therefore, the damage induced on the sample under investigation is very limited and further investigations can be performed on the same sample by means of other analytical techniques, by providing complementary information [11,12].

Moreover, ToF-SIMS has the capability to provide chemical imaging, which allows the identification and localization of the compounds characterizing the sample. Especially, ToF-SIMS spectrometry is particularly indicated for the identification and localization of organic compounds such as resins, oils, binders, dyes, lacquers, etc. difficult to analyze through common analytical techniques largely employed until now [11-16].

In this work, the chemical characterization of the constitutive materials and of the conservation state of gilt and painted leather by using MA-XRF, ATR-FTIR, and ToF-SIMS were carried out to localize and identify inorganic and organic species.

The achieved information on the constitutive materials, manufacturing technique, and degradation products can be very useful in establishing restoration and conservation interventions and to ensure a long and stable chemical-physical life to these precious works of art.

\section{Materials and Methods}

\subsection{Samples}

The investigated gilt and painted leather wall decorations have been sampled at the noble Palazzo Chigi in Ariccia (Rome, Italy). One of the peculiarities of this building is related to the good conservation state of the internal decoration such as the luxurious leather wallpapers still present in many environments. Nevertheless, fragmented and incomplete leather wallpapers, that will later form a leather museum within the building, were also found. The existing leather wallpapers of Palazzo Chigi were manufactured in Rome. Some of these were made in the typical style of the Renaissance tradition with a ritual design and other ones were made in the Venetian and Flemish style [5]. The leather fragments studied in this work are dated back to the XVII century and manufactured in high relief by embossing, according to the Flemish style.

\subsection{Macro X-ray Fluorescence (MA-XRF)}

An MA-XRF scanner prototype built by the INFN Roma TRE division and Ars Mensurae was employed. The scanner consists of an exchangeable head attached to a motorized $x-y$ stage. The scanning head is composed of a low-power Moxtek $₫$ tube with a Ta target and collimated to $1 \mathrm{~mm}$, a silicon drift detector (SDD), and a twin-laser focusing system. The images resolution is roughly $1 \mathrm{~mm}^{2}$ per pixel. For the present analysis, the tube operated at $37 \mathrm{kV}$ and $17 \mu \mathrm{A}$ with a dwell-time of $3 \mathrm{~s}$. This scanning head has been used in previous publications as a single-spot XRF instrument using a smaller X-ray tube [17]. In order to gather as much information as possible with the least scanning time, 3 zones, which are known as zones $1,2 \mathrm{a}$, and $2 \mathrm{~b}$ from samples 1 and 2 (dimensions $26 \times 22,21 \times 20$ and $11 \times 13 \mathrm{~mm}^{2}$, respectively) were selected for analysis (Figure 1a). The MA-XRF scanner was calibrated using SRM 1115-Commercial Bronze Standard for Optical Emission and X-ray Spectroscopic Analysis (NIST standard reference material) with the following composition expressed as mass fraction, in \%: Copper 87.96, Zinc 11.73, Lead 0.013, Iron 0.13, Tin 0.10, Nickel 0.074, and Phosphorus 0.05.

\subsection{Attenuated Total Reflectance-Fourier Transform Infrared Spectroscopy (ATR-FTIR)}

Attenuated Total Reflectance-Fourier transform infrared spectroscopy analysis was performed on the leather fragments. ATR-FTIR spectra for all the colored areas of the three painted leather pieces were recorded, which ranged from 3500 to $500 \mathrm{~cm}^{-1}$ (MID IR) and 1600 to $200 \mathrm{~cm}^{-1}$ (MID \& FAR IR) with a ThermoFisher®Nicolet iS50 FT-IR instrument, in Attenuated Total Reflectance (ATR) mode. The FT-IR system performance verification was accomplished through a fully automated internal validation wheel standard. The wheel automatically moves standard samples into the beam path at 
the appropriate times during the validation procedure. The samples are traceable to standards from the National Institute of Standards and Technology (NIST) [18]. The instrument is equipped with a diamond crystal and a $45^{\circ}$ incident beam. The spectral resolution was $4 \mathrm{~cm}^{-1}$ for both the series of spectral measurements. A total of 50 scans were accumulated for each spectrum. For a simultaneous comparison of all the ATR-FTIR spectra, please refer to supplementary material.

\subsection{Time of Flight Secondary Ion Mass Spectrometry (ToF-SIMS)}

ToF-SIMS experiments were performed with a TOF-SIMS5-300 mass spectrometer (ION-TOF $\mathrm{GmbH}$, Munster, Germany) equipped with a $30 \mathrm{KeV}$ Bi LMIG (liquid metal ion gun).

$\mathrm{A} \mathrm{Bi}_{3}{ }^{+}$ion beam was selected with an incidence angle of $45^{\circ}$ operating in a standard mode. The emitted secondary ions were accelerated to kinetic energy of 2 to $3 \mathrm{KeV}$ toward the field-free region. When necessary, charge neutralization was obtained by using a low-energy electron flood gun.

The ion beam was rastered over areas of $200 \mu \mathrm{m} \times 200 \mu \mathrm{m}$ and $500 \mu \mathrm{m} \times 500 \mu \mathrm{m}$ with an ion dose density below the static limit $\left(10-12 \mathrm{ion} / \mathrm{cm}^{2}\right)$. Both positive and negative polarity spectra and images $(128 \times 128$ pixels $)$ of elements and molecular fragments distributions were recorded. All secondary ion images shown in this paper were normalized to the total ion image. However, after this normalization process, the ion images are still strongly affected by topography effects. Mass spectra were internally calibrated using $\mathrm{H}^{+}, \mathrm{H}_{2}{ }^{+}, \mathrm{H}_{3}{ }^{+}, \mathrm{C}^{+}, \mathrm{CH}^{+}, \mathrm{CH}_{2}{ }^{+}$, and $\mathrm{CH}_{3}{ }^{+}$in a positive ion mode and $\mathrm{H}_{2}{ }^{-}, \mathrm{C}^{-}, \mathrm{CH}^{-}$, $\mathrm{CH}_{2}{ }^{-}$, and $\mathrm{OH}^{-}$in a negative mode, respectively. The data were acquired and processed using the SurfaceLab 6.4 software (ION-TOF GmbH, Munster, Germany).

\section{Results and Discussion}

MA-XRF, ATR-FTIR, and ToF-SIMS experiments were carried out on three samples of gilt and painted leather (Figure 1a). The samples consist of a leather support covered with a silver leaf and gold varnish. Nevertheless, some features can be appreciated among them. In samples 1 and 2, red and green pigments can be easily observed. On the contrary, in sample 2, small blue spots can be appreciated using an optical microscope (Figure $1 \mathrm{~b}$ (top)). High reliefs obtained by embossing the technique are more evident in sample 1. Lastly, in sample 3, in addition to the red pigment and the gold varnish, the silver leaf is more appreciable due to the embrittlement and lack of the overlapped gold varnish.

In Figure 1a, the red, blue, and green squares indicate the MA-XRF, ATR-FTIR, and ToF-SIMS area of analysis, respectively. Details of the constitutive materials for the three samples are shown in Figure $1 \mathrm{~b}$. The results obtained from the different regions investigated (leather support, silver leaf, gold varnish, blue, and red and green areas) are described below.

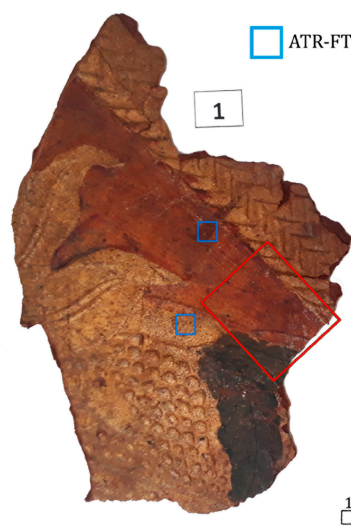

a)

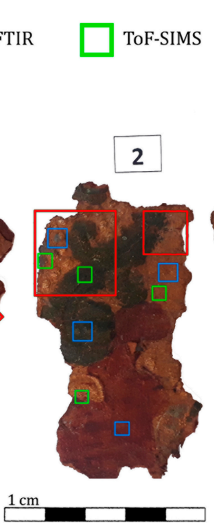

ב

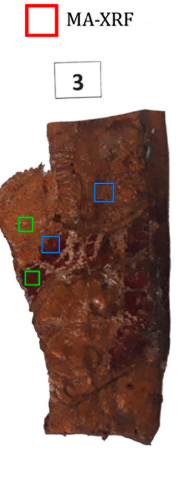

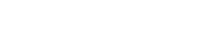

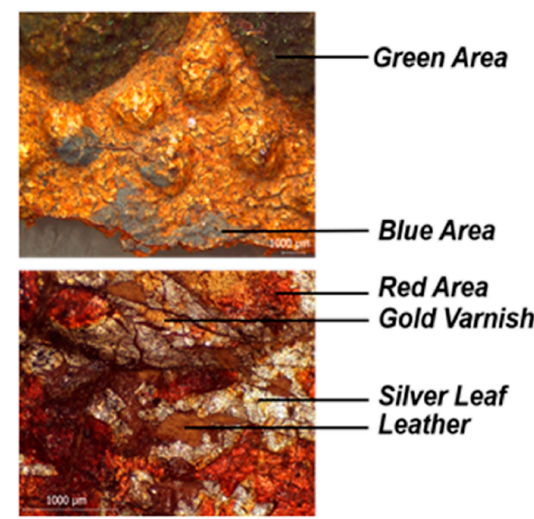

b)

Figure 1. Fragments of gilt and painted leather (a) and details and description of the constitutive materials (b). 


\subsection{Leather Support and Silver Leaf}

The first decorative layer applied on the leather surface is a silver leaf. In this case, ToF-SIMS results obtained in a positive ion mode, show the presence of sodium, magnesium, aluminum, silicon, potassium, calcium and oxygenated calcium ions, and silver and iron sulfates $\left(\mathrm{FeSO}_{4}{ }^{-}, \mathrm{m} / z 152\right.$ and $\mathrm{FeSO}_{5} \mathrm{H}^{-}, \mathrm{m} / \mathrm{z}$ 169).

Complementary elemental maps obtained from MA-XRF show calcium and iron equally distributed throughout the MA-XRF sampled regions from leather samples 1 and 2 (Figure S1). The presence of calcium can be attributed to the un-hairing process of leather tanning, which traditionally makes use of alkaline solutions such as lime or soda ash [4]. Regarding what concerns the iron, it should be considered that potash alum was commonly used in the tanning process in the past. Impure alum usually contained a great amount of iron sulfate. Moreover, potash alum obtained from naturally occurring alunite or alum-stone by roasting followed by lixiviation and crystallization can present a brownish or pinkish hue due to the presence of $\mathrm{Fe}_{2} \mathrm{O}_{3}$ [19]. In this context, iron is likely to be related to the tanning process itself.

Moreover, in the areas where the gold varnish cracked, oxidation damages of the exposed silver surface were revealed. In these regions, in fact, ToF-SIMS experiments detected clusters of silver, silver oxides, silver chlorides, and silver sulfides (Peaks and spectra are shown in Figure S2). In Figure 2, the corresponding positive ion maps are reported. The presence of $\mathrm{CN}^{-}(\mathrm{m} / \mathrm{z} 26), \mathrm{P}^{-}(\mathrm{m} / \mathrm{z} 31), \mathrm{CNO}^{-}$ $(\mathrm{m} / \mathrm{z} 42), \mathrm{PO}^{-}(\mathrm{m} / \mathrm{z} 47), \mathrm{PO}_{2}{ }^{-}(\mathrm{m} / \mathrm{z} 63)$, and $\mathrm{PO}_{3}{ }^{-}(\mathrm{m} / \mathrm{z} 79)$ in the negative ion mass spectra may suggest the use of proteinaceous compounds applied on the surface layers or arising from the animal glue used to adhere the silver leaf to the leather support. In fact, $\mathrm{CN}^{-}$and $\mathrm{CNO}^{-}$ions are characteristic of the peptide backbone fragmentation. Phosphate ions are usually detected in the presence of cellular material. In the same area, $\mathrm{Cl}^{-}(\mathrm{m} / \mathrm{z} 35)$ and $\mathrm{S}^{-}(\mathrm{m} / \mathrm{z} 32)$ were also detected.

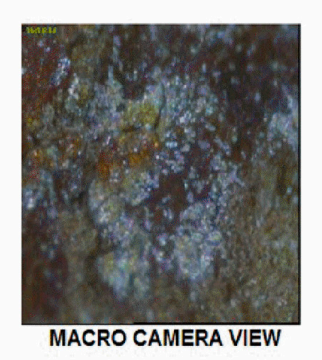

a)

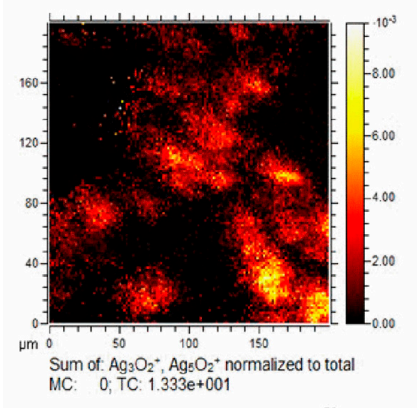

d)

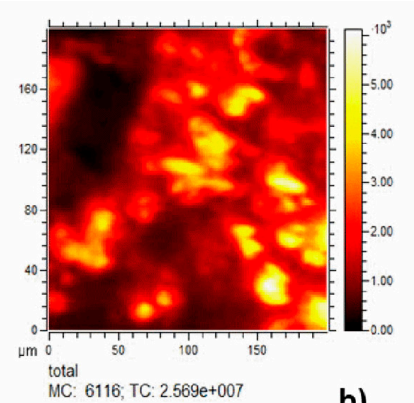

b)

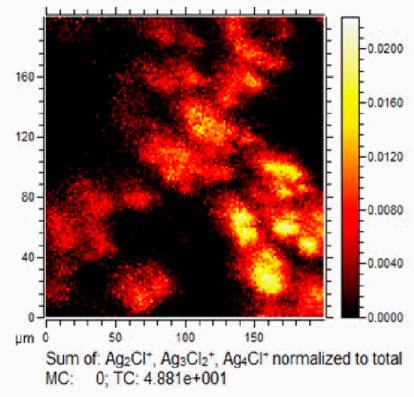

e)

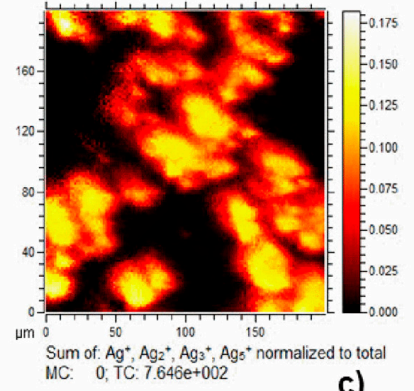

c)

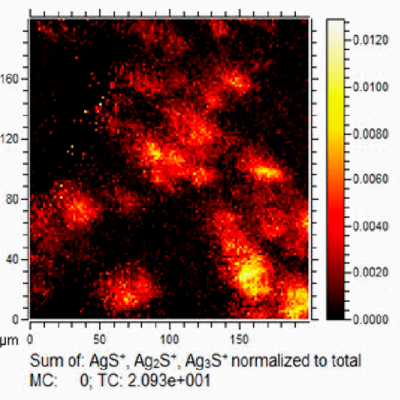

f)

Figure 2. Silver-containing compounds in the silver leaf. (a) Macro camera view of the area where ToF-SIMS images were acquired (area of $200 \mu \mathrm{m} \times 200 \mu \mathrm{m}$ ). (b-f) TOF-SIMS ion images were recorded in the positive ion mode, (b) total ion image, (c) ion image of the sum of silver ions (sum of: $\mathrm{Ag}^{+}$, $m / z$ 107, $\mathrm{Ag}_{2}{ }^{+}, m / z 214 ; \mathrm{Ag}_{3}{ }^{+}, m / z 321, \mathrm{Ag}_{5}{ }^{+}, \mathrm{m} / \mathrm{z} 534$ ), (d) ion image of the sum of silver oxides (sum of: $\left.\mathrm{Ag}_{3} \mathrm{O}_{2}{ }^{+}, m / z 353 ; \mathrm{Ag}_{5} \mathrm{O}_{2}{ }^{+}, m / z 567\right)$, (e) ion image of the sum of silver chlorides (sum of: $\mathrm{Ag}_{2} \mathrm{Cl}^{+}$, $m / z$ 249, $\left.\mathrm{Ag}_{3} \mathrm{Cl}_{2}{ }^{+}, m / z 391, \mathrm{Ag}_{4} \mathrm{Cl}^{+}, \mathrm{m} / \mathrm{z} 463\right)$, and (f) ion image of the sum of silver sulfides $\left(\mathrm{AgS}^{+}\right.$, $\left.\mathrm{m} / \mathrm{z} 139, \mathrm{Ag}_{2} \mathrm{~S}^{+}, \mathrm{m} / \mathrm{z} 246, \mathrm{Ag}_{3} \mathrm{~S}^{+}, \mathrm{m} / \mathrm{z} 353\right)$. 


\subsection{Gold Varnish}

In the gold areas, ToF-SIMS experiments revealed the presence of sodium, magnesium, aluminum, silicon, potassium, silver, calcium, calcium-oxygen containing ions, lead, and lead-oxygen containing ions.

MA-XRF elemental maps (Figure S3) also show lead widespread all over the gold and red portions of sample 1 and in correspondence of the gold area in sample 2 .

The presence of lead ions in the gold varnish can be explained with the use of lead as siccative and/or an inorganic pigment. In this case, the inorganic pigment could be attributed to the presence of massicot $(\mathrm{PbO})$, which is an inorganic yellow pigment.

In the positive ToF-SIMS spectra (Figure 3) protonated linoleic $\left(\mathrm{C}_{18} \mathrm{H}_{33} \mathrm{O}_{2}{ }^{+}, \mathrm{m} / z\right.$ 281), stearic $\left(\mathrm{C}_{18} \mathrm{H}_{37} \mathrm{O}_{2}{ }^{+}, \mathrm{m} / \mathrm{z} 285\right)$, arachidic $\left(\mathrm{C}_{20} \mathrm{H}_{41} \mathrm{O}_{2}{ }^{+}, \mathrm{m} / \mathrm{z} 314\right)$, behenic $\left(\mathrm{C}_{22} \mathrm{H}_{45} \mathrm{O}_{2}{ }^{+}, \mathrm{m} / \mathrm{z} 341\right)$, nervonic $\left(\mathrm{C}_{24} \mathrm{H}_{47} \mathrm{O}_{2}{ }^{+}, \mathrm{m} / \mathrm{z} 367\right)$, and lignoceric $\left(\mathrm{C}_{24} \mathrm{H}_{49} \mathrm{O}_{2}{ }^{+}, \mathrm{m} / \mathrm{z} 369\right)$ acid ion signals can be observed. The presence of these fatty acids was detected in most of the spectra collected on the different selected areas (gold, blue, green, and red). In some spectra, protonated arachidonic acid $\left(\mathrm{C}_{20} \mathrm{H}_{33} \mathrm{O}_{2}{ }^{+}, m / z 305\right)$ was also detected (data not shown).

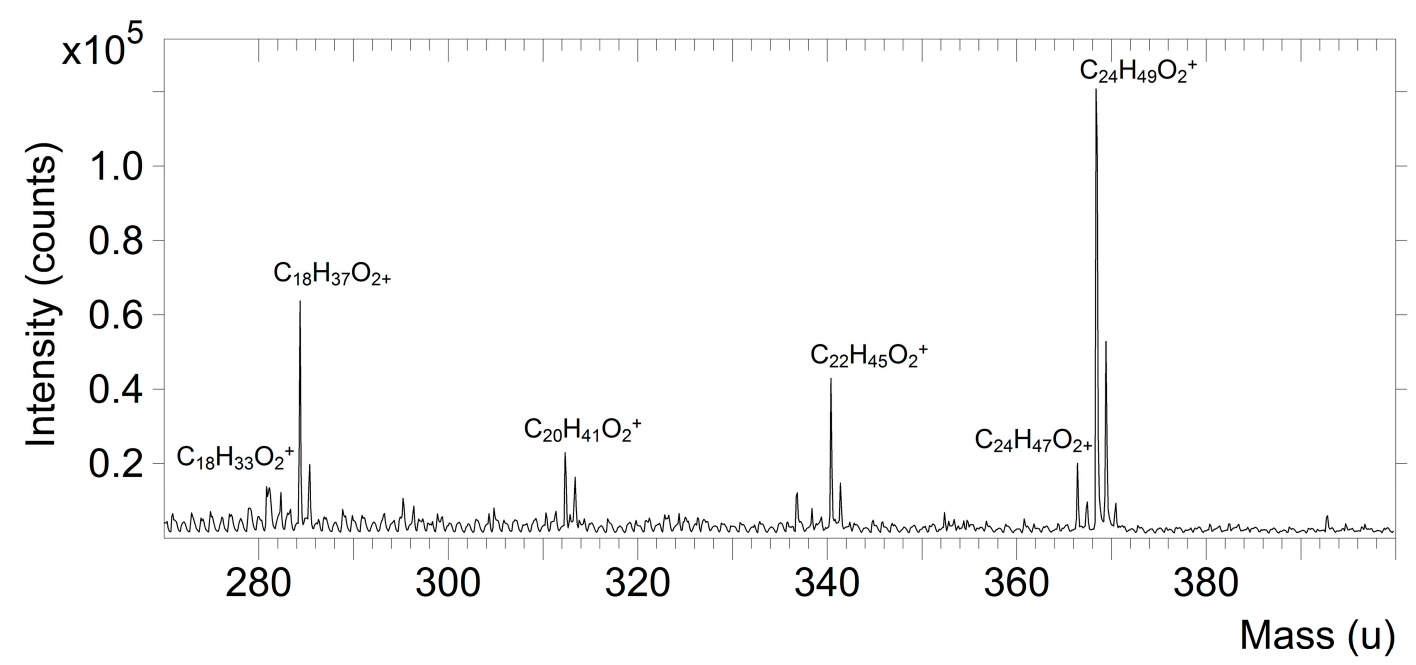

Figure 3. Part of positive ion mass spectra extracted from the gold area and showing the protonated fatty acids: linoleic $\left(\mathrm{C}_{18} \mathrm{H}_{33} \mathrm{O}_{2}{ }^{+}, \mathrm{m} / \mathrm{z} 281\right)$, stearic $\left(\mathrm{C}_{18} \mathrm{H}_{37} \mathrm{O}_{2}{ }^{+}, \mathrm{m} / \mathrm{z} 285\right)$, arachidic $\left(\mathrm{C}_{20} \mathrm{H}_{41} \mathrm{O}_{2}{ }^{+}, m / z\right.$ 314), behenic $\left(\mathrm{C}_{22} \mathrm{H}_{45} \mathrm{O}_{2}{ }^{+}, \mathrm{m} / \mathrm{z} 341\right)$, nervonic $\left(\mathrm{C}_{24} \mathrm{H}_{47} \mathrm{O}_{2}{ }^{+}, \mathrm{m} / \mathrm{z} 367\right)$, and lignoceric $\left(\mathrm{C}_{24} \mathrm{H}_{49} \mathrm{O}_{2}{ }^{+}, \mathrm{m} / \mathrm{z} 369\right)$.

The presence of linoleic, stearic, and arachidic fatty acids together with the lead ions in the gold varnish seems to be in agreement with the ancient recipes for obtaining the golden surface by stating that this was usually constituted by heat-bodied linseed oil with lead components [1,3]. However, further studies will be performed to validate the presence of other organic colorants in the gold area. In fact, arachidonic, linoleic, and lignoceric acids could be ascribed to the presence of aloe used as an organic colorant in the gold varnish $[1,3,20]$.

The ATR-FTIR spectra obtained in the region of 3500 to $200 \mathrm{~cm}^{-1}$ for the gold varnish on sample 2 are shown in Figure 4a,b. Main spectral features are found at $1629 \mathrm{~cm}^{-1}(v[\mathrm{C}=\mathrm{O}]$, in amide I), $1542 \mathrm{~cm}^{-1}\left(v[\mathrm{C}-\mathrm{N}]\right.$, and in-plane bending of $\mathrm{N}-\mathrm{H}$, both from amide II), $1459 \mathrm{~cm}^{-1}$ (bending of C-H and $v_{3}[\mathrm{C}-\mathrm{O}]$ from $\mathrm{CO}_{3}{ }^{2-}$ group), $1316 \mathrm{~cm}^{-1}(v[\mathrm{C}-\mathrm{O}]), 1031 \mathrm{~cm}^{-1}\left(\rho\left[\mathrm{CH}_{3}\right]\right)$, and $1006 \mathrm{~cm}^{-1}\left(\rho\left[\mathrm{CH}_{3}\right]\right)$ (extended attributions are reported in supplementary information and shown in Figure S4) [21-26]. The found vibrations confirm the presence of a mixture of oils and proteins, the former being used as a painting medium and the latter constituting both a component of the medium itself and an adhesive layer between the leather substrate and the silver leaf. When observed at low magnification with the stereomicroscope, the silver leaf shows a large number of cracks and lacks exposure of the underlying layers. It allows for the IR absorption by the adhesive. No clear signal from pigments conferring the yellow coloration was recognized. ATR-FTIR spectra of the gold area in sample 3 
(Figure 4c) showed the presence of an additional compound. The comparison with a reference spectra of rosin oil from Pine-tree, comparable with those found in literature $[8,26,27]$, led to attribute the unknown compound to the class of diterpenoid resins, such as colophony (attributions are reported in supplementary information).
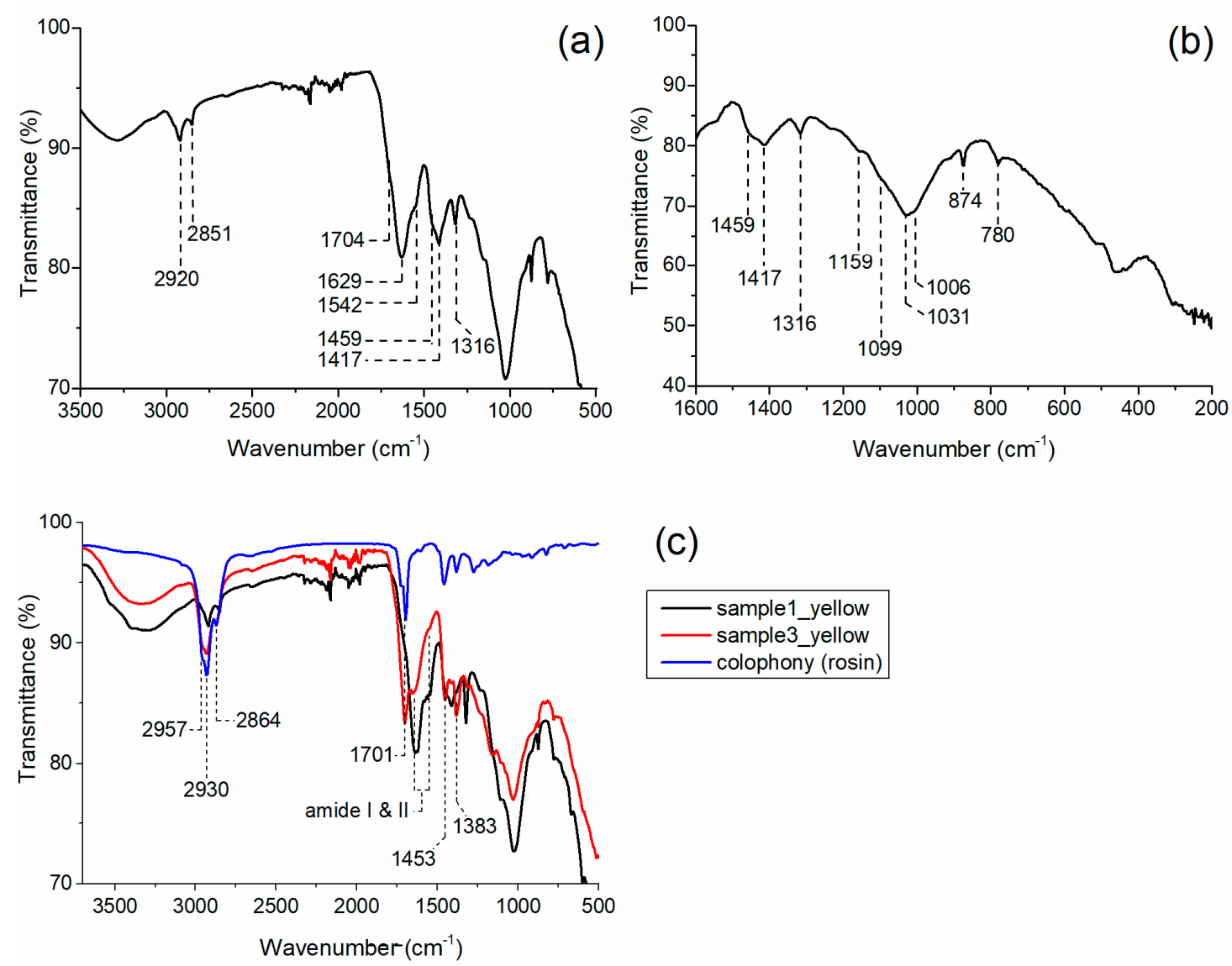

(c)

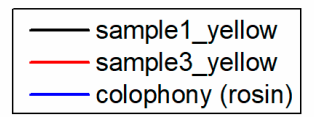

Figure 4. ATR-FTIR spectra of the gold varnish in the range $3500 \div 500 \mathrm{~cm}^{-1}$ (a) and in the range, $1600 \div 200 \mathrm{~cm}^{-1}($ b), showing spectral features compatible with a mixture of proteins and oils. Comparison between the gold varnish from sample 1 and 3 with colophony reference spectrum (c), confirming its presence in sample 3.

\subsection{Blue Areas}

In the blue areas of sample 2, several inorganic ions were detected: sodium, potassium, calcium, and calcium-oxygen containing ions (Figure S5).

In addition, lead ion, a cluster of lead oxides, and lead hydroxides were found (Peaks and spectra are shown in Figure S6).

The positive ion ToF-SIMS spectrum (Figure 5) of the blue area in sample 2 shows peaks related to the indigotin protonated molecular ion $\left(\left[\mathrm{M}+\mathrm{H}^{+}\right]\right)$at $m / z 263\left(\mathrm{C}_{16} \mathrm{H}_{11} \mathrm{~N}_{2} \mathrm{O}_{2}{ }^{+}\right)$and to its characteristic fragmentation at $m / z 247\left(\mathrm{C}_{16} \mathrm{H}_{11} \mathrm{~N}_{2} \mathrm{O}^{+}\right)$. These two ion peaks indicate the use of indigo as a pigment for the blue areas. Moreover, protonated linoleic $\left(\mathrm{C}_{18} \mathrm{H}_{33} \mathrm{O}_{2}{ }^{+}\right)$, stearic $\left(\mathrm{C}_{18} \mathrm{H}_{37} \mathrm{O}_{2}{ }^{+}\right)$, and lignoceric $\left(\mathrm{C}_{24} \mathrm{H}_{49} \mathrm{O}_{2}{ }^{+}\right)$acids were observed (Figure 5).

The diacylglycerols of stearic and palmitic acids, respectively, at $m / z 523$ and $m / z 551$, were also found (data not shown). The fragmentation of these molecules usually generates the signals of the corresponding fatty acids. In this case, no signals related to the palmitic acid were revealed. In addition, in this area, the presence of lead soaps of linoleic acid at $\mathrm{m} / \mathrm{z} 489$ was revealed (data not shown). 


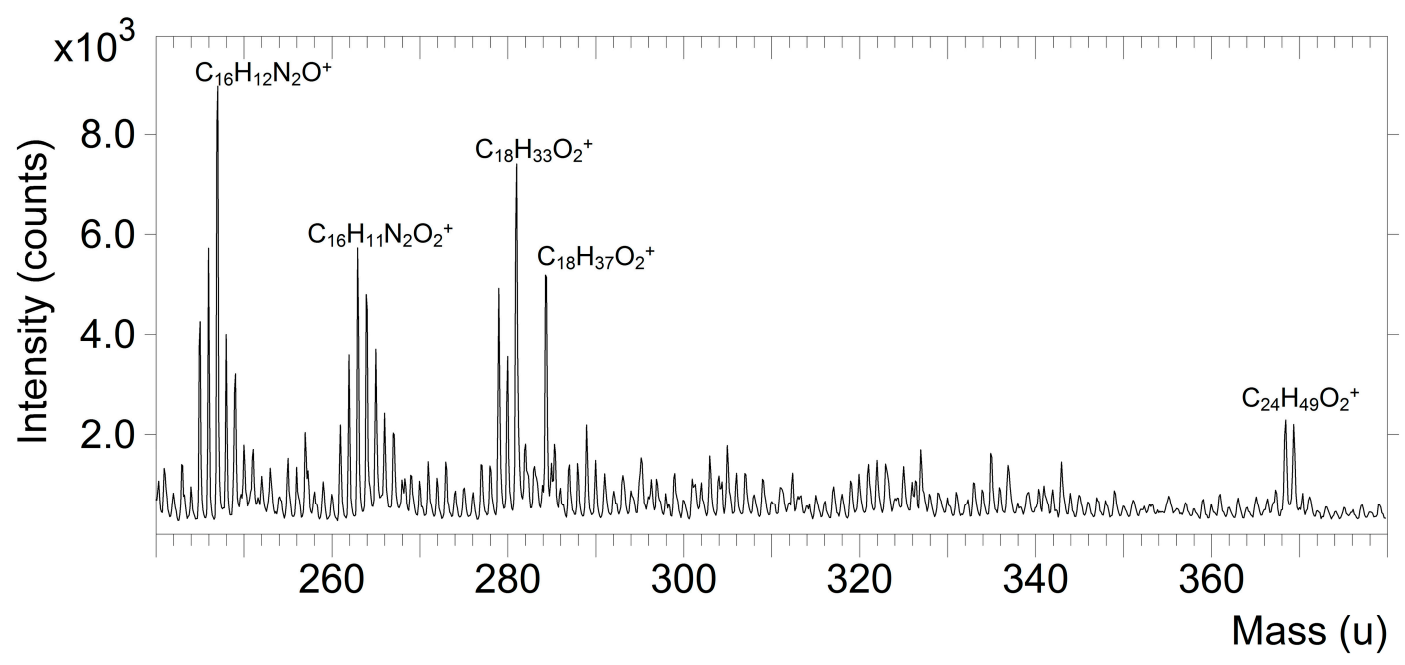

Figure 5. Part of the positive ion mass spectra extracted from the blue area and showing indigotin protonated ion $\left(\mathrm{C}_{16} \mathrm{H}_{11} \mathrm{~N}_{2} \mathrm{O}_{2}{ }^{+}, m / z 263\right)$, indigotin fragment ion $\left(\mathrm{C}_{16} \mathrm{H}_{11} \mathrm{~N}_{2} \mathrm{O}^{+}, m / z 247\right)$, and protonated fatty acids: linoleic $\left(\mathrm{C}_{18} \mathrm{H}_{33} \mathrm{O}_{2}{ }^{+}, m / z 281\right)$, stearic $\left(\mathrm{C}_{18} \mathrm{H}_{37} \mathrm{O}_{2}{ }^{+}, m / z 285\right)$, and lignoceric $\left(\mathrm{C}_{24} \mathrm{H}_{49} \mathrm{O}_{2}{ }^{+}, m / z 369\right)$.

The lead soaps formation is a topic of major importance in conservation and restoration interventions since, among others, it is indicated as the cause of the increased transparency of the paint layers [28-30]. Furthermore, the exposure to environmental conditions can be responsible for this phenomenon since it can lead to the formation of superficial crusts due to the remineralization of compounds through the reactions with the environment itself [30,31].

On the other hand, in the negative mode, several clusters of lead oxides and lead hydroxides were detected (peaks and spectra are shown in Figure S7). All these ions suggest the presence of lead white as a substrate of indigo. Additionally, when observing the MA-XRF elemental maps of lead, it is possible to appreciate a higher concentration of lead in the blue pigment area (Figure 6). The results obtained indicate that the indigo pigment was used in the oil binder and it was mixed with lead white.

\section{Analyzed area}

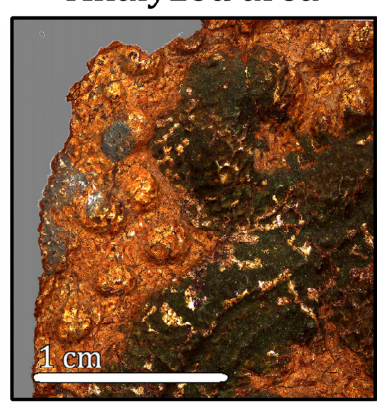

$\mathrm{Pb}$

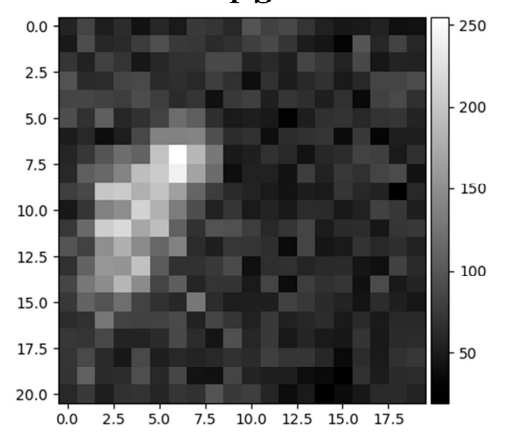

Figure 6. MA-XRF elemental map of Pb from leather sample 2 (zone 2a).

Lastly, the negative ion mass spectra (Figure 7) shows peaks at $\mathrm{m} / \mathrm{z} 259, \mathrm{~m} / \mathrm{z} 278$, and $\mathrm{m} / \mathrm{z} 313$. The signal at $\mathrm{m} / \mathrm{z} 313$ could be attributable to the 7-oxo-dehydroabietic acid of the colophony and the peaks at $m / z 259$ and $m / z 278$ to its fragmentation process [32]. The presence of colophony as resin found in the leather fragments was detected by ATR-FTIR analysis in the other samples. 


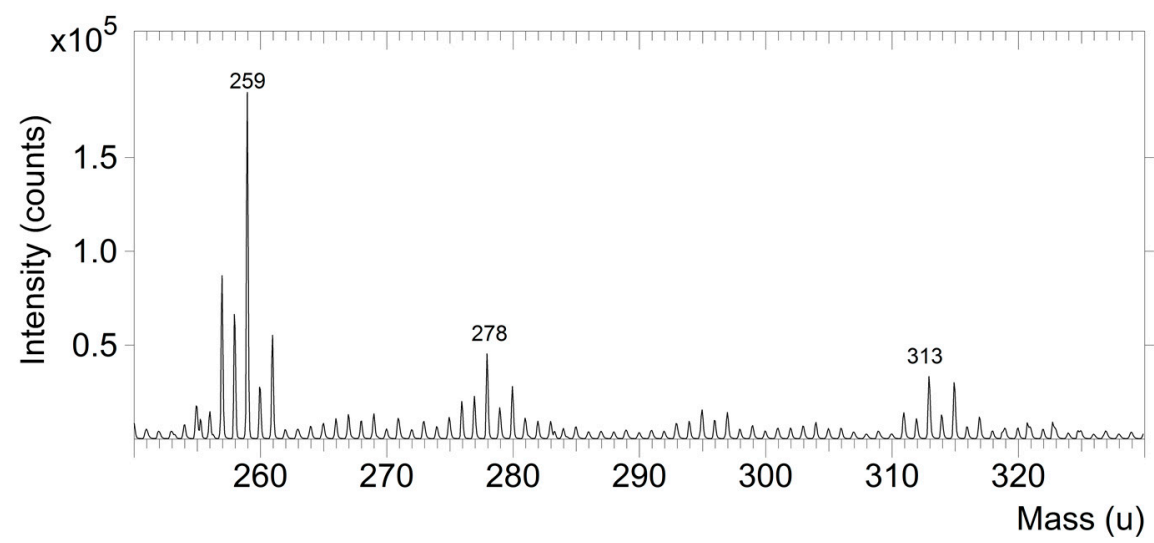

Figure 7. Part of negative ion mass spectra extracted from the blue area and showing the 7-oxo-dehydroabietic acid ( $\mathrm{m} / \mathrm{z} 313)$ of the colophony and its fragments ions ( $\mathrm{m} / \mathrm{z} 259$ and $\mathrm{m} / \mathrm{z} 278)$.

ATR-FTIR spectra of the blue area (Figure 8) show spectral features common to those obtained from gold varnish. Characteristic peaks are at $1079 \mathrm{~cm}^{-1}$ (assignable to $\mathrm{CO}_{3}{ }^{-2}$ group), $1044 \mathrm{~cm}^{-1}$ $\left(\rho\left[\mathrm{CH}_{3}\right]\right.$, and $v_{1}[\mathrm{C}-\mathrm{O}]$ from $\mathrm{CO}_{3}{ }^{-2}$ group), the couple at 680 and $658 \mathrm{~cm}^{-1}\left(v_{4}[\mathrm{C}-\mathrm{O}]\right.$ from $\mathrm{CO}_{3}{ }^{-2}$ group and bending of $-\mathrm{O}-\mathrm{C}=\mathrm{O}$, respectively), and the peak at $596 \mathrm{~cm}^{-1}$ (bending of $-\mathrm{NCO}$ group and $v_{4}[\mathrm{~S}-\mathrm{O}]$ from $\mathrm{SO}_{4}{ }^{-2}$ group) (extended attributions are reported in supplementary information and shown in Figure S4) [32-34]. These features confirm the hypothesis that the blue color is made with indigo on a lead carbonate (cerussite, biacca) substrate. No signal attributed to indigo was revealed by ATR-FTIR and this could be explained by considering the light hue of the analyzed area, which required a low amount of the blue organic pigment. The intensity of the bands related to phosphorus-containing, $\mathrm{N}-\mathrm{C}$, and $\mathrm{N}-\mathrm{H}$ groups is to be put in relation to the higher presence of proteinaceous material in the painting medium. The presence of sulphate ions is well supported by the evidence, but its origin is not clear. It could have originated by the defibered border of the leather fragment and it may be related to the impurities of alum (tanning agent, as specified in the first section of the Leather and Silver leaf).
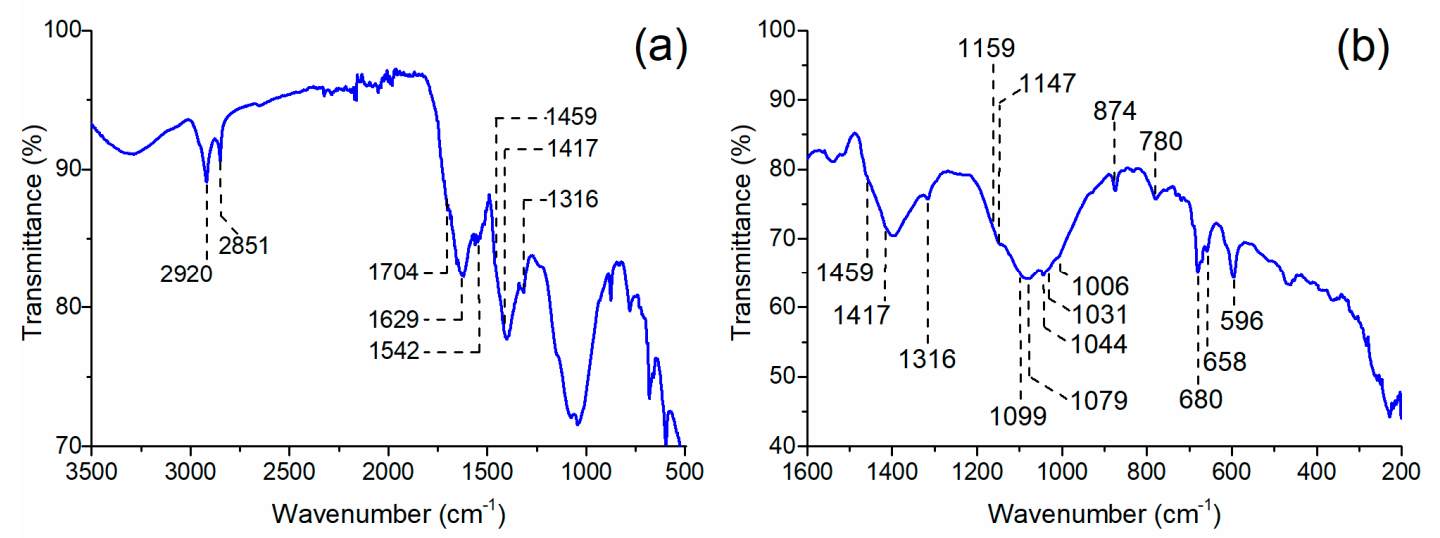

Figure 8. ATR-FTIR spectra of the blue areas in the range $3500 \div 500 \mathrm{~cm}^{-1}$ (a) and in the range $1600 \div 200 \mathrm{~cm}^{-1}($ b). In addition to spectral features common with gold varnish, characteristic peaks and shoulders $\left(1079,1044,690,680,671,658,616\right.$, and $\left.596 \mathrm{~cm}^{-1}\right)$ attribute the blue pigment as indigo on a lead carbonate substrate, which is coupled with the presence of sulphates.

\subsection{Green Areas}

ToF-SIMS results from the green areas detected the presence of sodium, magnesium, aluminum, silicon, potassium, calcium ions $\left(\mathrm{Ca}^{+}\right.$and $\left.\mathrm{CaOH}^{+}\right)$, silver $(\mathrm{m} / \mathrm{z}$ 107), lead, and lead-oxygen containing ions $\left(\mathrm{Pb}^{+}\right.$and $\left.\mathrm{PbOH}^{+}\right)$. All these ions are characteristics of the surrounding gold varnish, silver leaf, and leather, as mentioned previously. 
Furthermore, the detection and localization of $\mathrm{Cu}^{+}(\mathrm{m} / z$ 63) (Figure 9$)$ in the green areas suggest the use of a copper-based green pigment. The signal distribution appears strongly influenced by the surface roughness of the sample. Thus, the mapping of the copper ion signal was normalized to the total ion image in order to minimize topological effects.

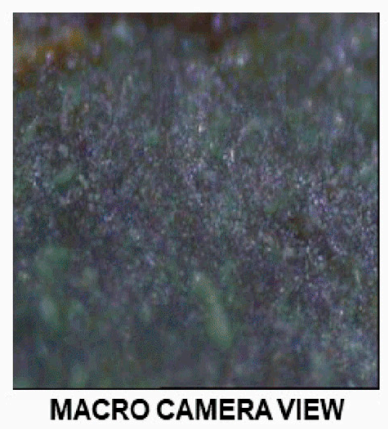

a)

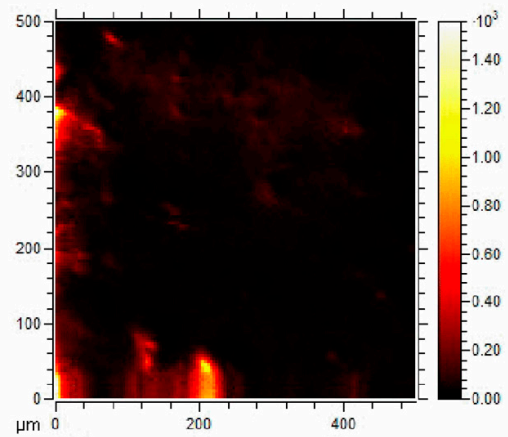

b)

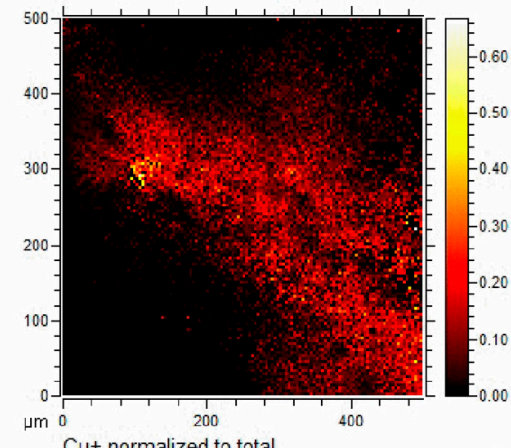

c)

Figure 9. ToF-SIMS ion images are recorded in the positive ion mode in the green area. (a) Macro camera view of the area where ToF-SIMS images were acquired (area of $500 \mu \mathrm{m} \times 500 \mu \mathrm{m}$ ), (b) total ion image, and (c) ion image of the copper ion $\left(\mathrm{Cu}^{+}, \mathrm{m} / \mathrm{z} 63\right)$.

The presence of copper is further confirmed by the MA-XRF elemental maps where it is possible to observe that this element is present as a major component only in the green areas (Figure 10).
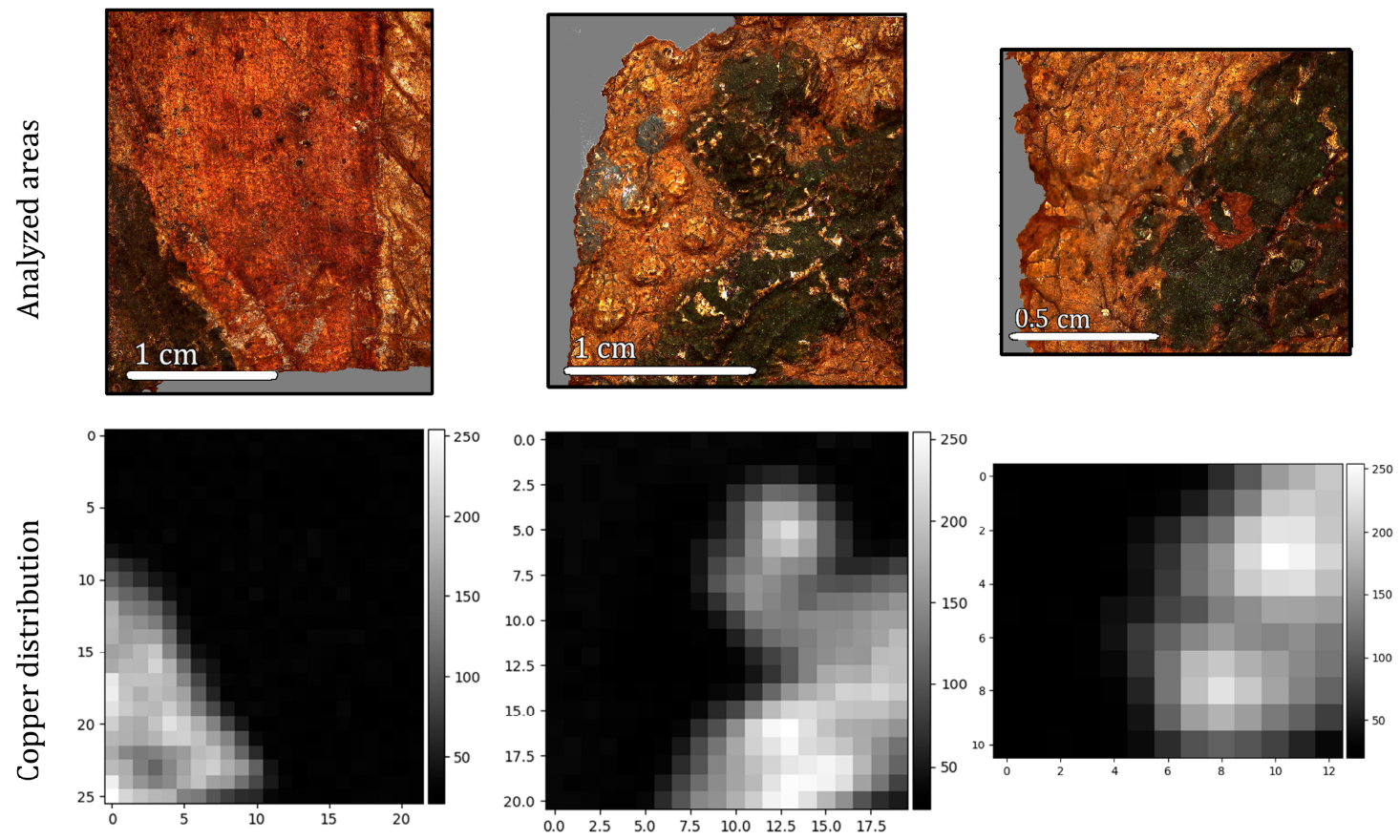

Figure 10. MA-XRF elemental maps of $\mathrm{Cu}$ obtained from leather samples 1 and 2 (zones 1, 2a, and 2b from left to right).

On the other hand, the negative ion maps of the green area (Figure 11) show the presence of two fragments $\left(\mathrm{CHO}_{2}{ }^{-}, \mathrm{m} / z 45\right.$, and $\mathrm{CuOH}^{-}, \mathrm{m} / \mathrm{z}$ 80) that could be ascribed to the presence of verdigris or copper resinate, which are two typical green pigments largely used in oil paint $[1,3]$. 


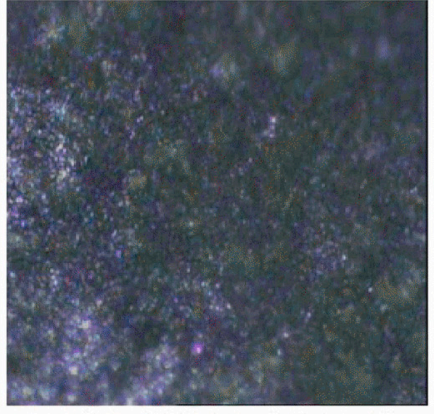

MACRO CAMERA VIEW

a)

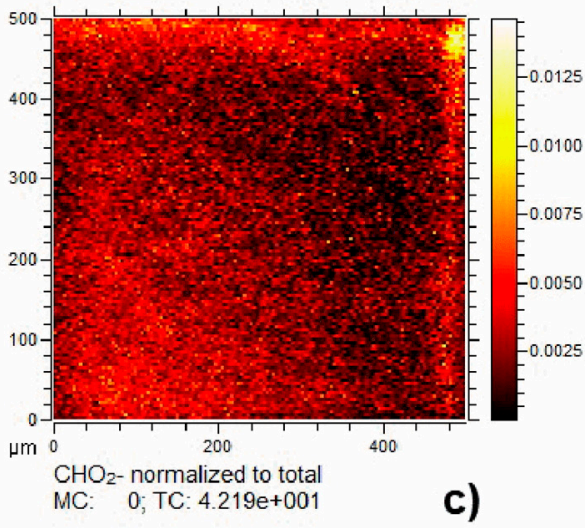

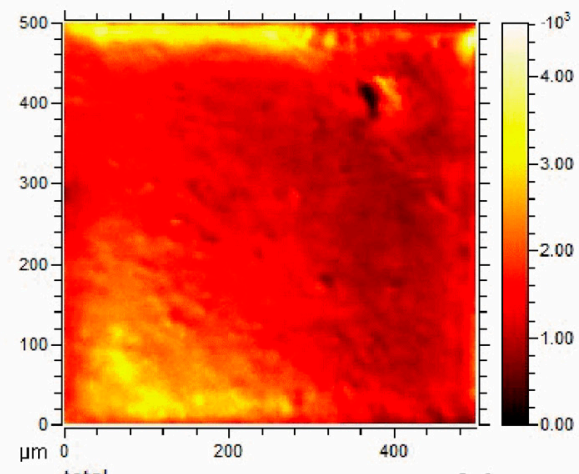

total MC: $4620 ;$ TC: $2.527 \mathrm{e}+007$

b)

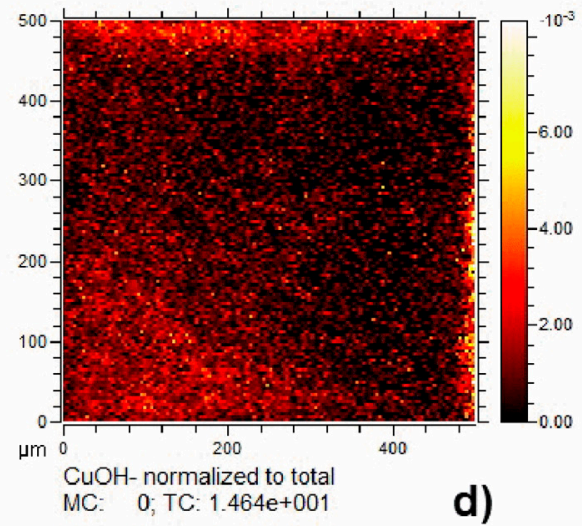

Figure 11. TOF-SIMS ion images recorded in the negative ion mode in the green area. (a) Macro camera view of the area where ToF-SIMS images were acquired (area of $500 \mu \mathrm{m} \times 500 \mu \mathrm{m}$ ), (b) total ion image, $(\mathbf{c}, \mathbf{d})$ ion images of the $\mathrm{CHO}_{2}{ }^{-}(\mathrm{m} / \mathrm{z} 45)$, and $\mathrm{CuOH}^{-}(\mathrm{m} / \mathrm{z}$ 80) fragment ions ascribed to the presence of verdigris.

Besides $\mathrm{CN}^{-}, \mathrm{P}^{-}, \mathrm{CNO}^{-}, \mathrm{PO}^{-}, \mathrm{PO}_{2}{ }^{-}$, and $\mathrm{PO}_{3}{ }^{-}$ions in the negative ion mass spectra were detected, which suggests the use of proteinaceous compounds.

In the same area, especially in the regions where the silver surface is more exposed, $\mathrm{Cl}^{-}, \mathrm{S}^{-}$, and silver chlorides $(\mathrm{m} / \mathrm{z} 321$ and 463$)$ were found.

ATR-FTIR spectra for green areas are shown in Figure 12. Spectral features common to gold varnish and blue areas can be found, but the main peak is centered at $1609 \mathrm{~cm}^{-1}(v[\mathrm{COO}]$ asymmetric) instead of $1629 \mathrm{~cm}^{-1}$ and the peak at $1316 \mathrm{~cm}^{-1}$ is much more intense. Characteristic peaks are at $1362 \mathrm{~cm}^{-1}\left(v[\mathrm{C}-\mathrm{O}]\right.$ from oxalate and $\left.\delta\left[\mathrm{CH}_{3}\right]\right), 821 \mathrm{~cm}^{-1}(\delta[\mathrm{O}-\mathrm{C}-\mathrm{O}]), 494 \mathrm{~cm}^{-1}(v[\mathrm{Cu}-\mathrm{O}])$, and $376 \mathrm{~cm}^{-1}$ $(v[\mathrm{Cu}-\mathrm{O}])[35-37]$. All these features suggest that green is a mixture of verdigris (copper acetate, as pigment) and oils (as a medium). The sharp peaks at 1362 and $821 \mathrm{~cm}^{-1}$ could be related to the presence of oxalate salts [38], which are not present in the other colored areas. Oxalate ions have been proposed as the resulting product of the degradation of the binding matrix (oily painting medium) [39,40], especially in the presence of lead-based and copper-based pigments [41]. The strong correlation between the presence of copper-based pigments and formation of oxalate salts has also been reported in the literature [40]. This gave reason for the selective presence of oxalate signals only in some of the areas analyzed. 

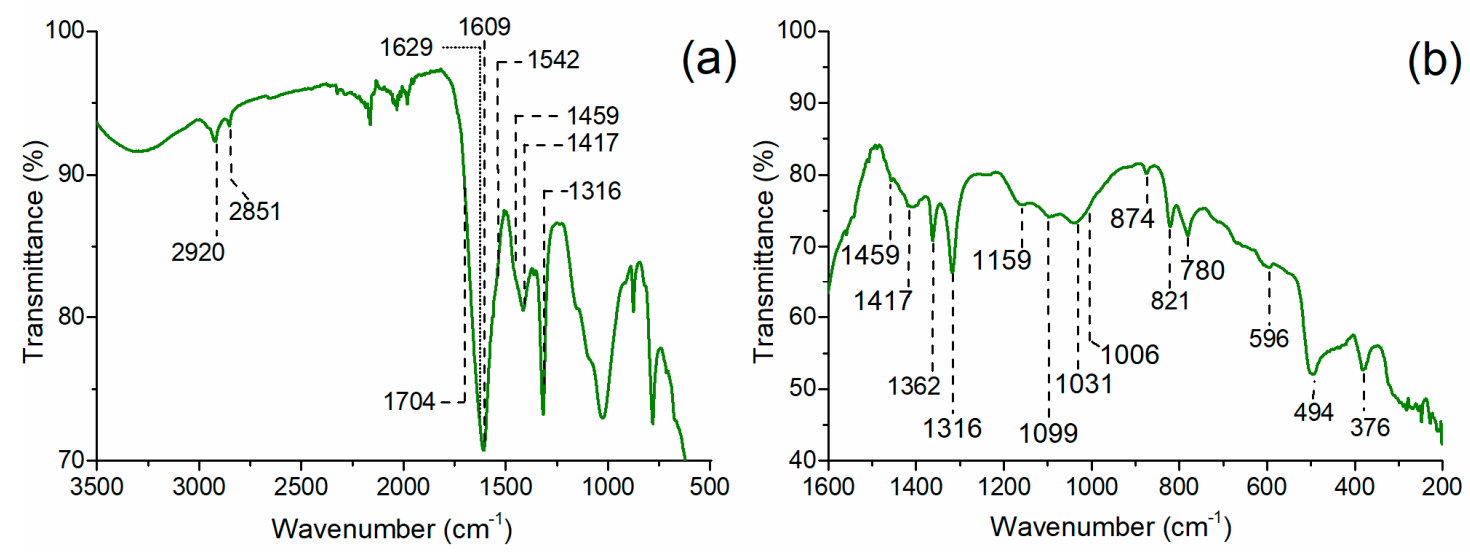

Figure 12. ATR-FTIR spectra of the green areas in the range of 3500 to $500 \mathrm{~cm}^{-1}$ (a) and in the range of 1600 to $200 \mathrm{~cm}^{-1}$ (b). In addition to spectral features common with gold varnish, characteristic peaks $\left(1609,1362,821,494\right.$, and $\left.376 \mathrm{~cm}^{-1}\right)$ attributed the green pigment as verdigris (copper acetate), which, in part, was altered, which formed copper oxalates.

\subsection{Red Areas}

The studies aimed to find that the red lake did not produce satisfactory results. It should be highlighted that a clear attribution of some of the peaks present in the mass spectra related to the red areas was difficult to obtain due to the presence of the ion peaks with a high intensity related to the fatty acids and lead oxides present on the underlying gold varnish. A further investigation of the red areas must be necessary to define their nature. Similarly, ATR-FTIR spectra resulted in the same spectral features shown for the gold varnish for both the spectral ranges (Figure 13). On the whole, it can be claimed that gold-yellow and red areas do not show characteristic features. The reason for this evidence could lie on the nature of the colored oils for painting, which are a very fine dispersion of solid granules of pigments in the mass of the medium. This is, in part, confirmed by the fact that the areas where signals were more efficiently collected are covered with the green and blue painting, which are much denser and opaquer by eye, as well. A further investigation of the red areas must be necessary to define their nature first via in situ XRF measurements with a portable instrument for a tailored sampling and, then, via investigations of cross-sectioned samples carried out by means of scanning electron microscopy coupled with energy dispersive spectroscopy (SEM-EDS) [10,42].
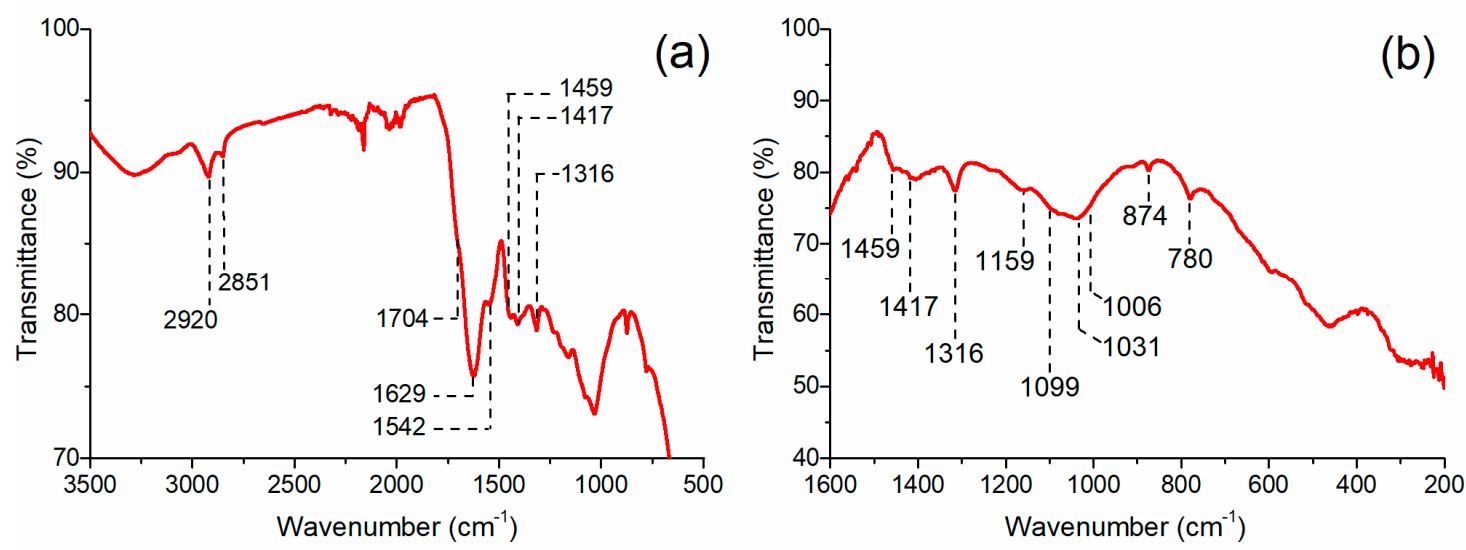

Figure 13. ATR-FTIR spectra of the red areas ranging from 3500 to $500 \mathrm{~cm}^{-1}$ (a) and in the range of 1600 to $200 \mathrm{~cm}^{-1}$ (b). All the spectral features are in common with the gold varnish and it was not possible to identify the nature of the pigment or coloring agent. 


\section{Conclusions}

The multi-analytical approach used in this work was useful to obtain information at different depths of the constitutive materials, manufacturing technique, and degradation products of the gilt and painted leather wallpapers, which decorate one of the most important and fascinating ancient noble palaces in Rome's outskirt.

ToF-SIMS was mainly used as a surface sensitive technique for revealing organic and inorganic compounds involved in the painting layer. On the other hand, although ATR-FTIR works at a different depth scale, FTIR spectra supported ToF-SIMS results. Lastly, MA-XRF analysis was crucial to validate the considerations done at the micrometer scale about the inorganic components on a larger area.

In this work, most of the constitutive materials and related degradation products were identified. However, gilt and painted leathers still represent a unique challenge considering the degradation phenomena occurring in these samples where metals and organic compounds are in intimate contact with living matter.

The stratigraphy of the samples was discovered to be composed of a leather support, animal glue, silver leaf, gold varnish, and, lastly, an eventual colored layer (red, green, or blue).

On the basis of these results, particular advices should be given to restaurateurs and conservators in order to prevent the tarnishing of the silver leaf. This phenomenon could lead to the loss of the original contrast among colors, which affects the overall visual perception of the represented figures. In addition, the exposure in a controlled environment could be considered the best choice to preserve these decorative materials. Lastly, considering the brittleness of the painting layer, the use of consolidants to prevent progressive fragmentation and delamination and avoid any mechanical stress is strongly suggested.

Supplementary Materials: The following are available online at http://www.mdpi.com/2076-3417/9/15/3016/s1.

Author Contributions: M.I. and V.G. drafted the work and conducted ToF-SIMS and FT-IR experiments. G.D.C. and G.I. revised and commented on the manuscript. S.L. conducted MA-XRF experiments and interpreted the data. S.R. conducted MA-XRF experiments. A.F. and P.B. developed the new XRF readout used in this work. L.T. designed the research, conceptualized, and reviewed the paper.

Funding: L.T. and A.F. would like to thank Fondazione Roma (Grant 5229441F37) for research funding. We also acknowledge funding from Regione Lazio under the Project "MUSA" n. B86C17000280002, Project ADAMO n. B86C18001220002 of the Excellence Centre at the Lazio Technological District for Cultural Heritage (DTC), and Marie Skłodowska-Curie Actions Innovative Training Networks, grant agreement No. 766311.

Acknowledgments: The Surface Analysis Laboratory Roma Tre is part of laboratories within the Italian Institute for Nuclear Physics (INFN) network CHNet and the Excellence Center of the Lazio Technological District for Cultural Heritage (DTC). The authors also acknowledge Arch. Francesco Petrucci to provide the leather fragments and Marcella Ioele for useful discussions.

Conflicts of Interest: The authors declare no conflict of interest. The funders had no role in the design of the study, in the collection, analyses, or interpretation of data, in the writing of the manuscript, or in the decision to publish the results.

\section{References}

1. De Boer, M.P.; Groves, R.; Koldeweij, E. Gilt Leather Artefacts: White Paper on Material Characterization and Improved Conservation Strategies within NICAS; Delft University of Technology: Delft, The Netherlands, 2016.

2. Calnan, C. The conservation of Spanish gilt leather-An introduction. Stud. Conserv. 2016, 37, $23-26$. [CrossRef]

3. De Boer, M.P.; Groves, R.; Koldeweij, E. Gilt leather conservation-A critical review to promote improved conservation strategies. In Proceedings of the 18th ICOM-CC Triennial Conference, Copenhagen, Denmark, 4-8 September 2017.

4. Mannina, L.; Lombardo, A. Diagnostic analyses for the study of materials, technique and state of preservation of a gilt and painted leather of the XVIII Century. Procedia Chem. 2013, 8, 202-211. [CrossRef]

5. Petrucci, F. Vita e arte negli arredi dei palazzi barocchi tra tradizione e modernità. In Dentro Il Palazzo; Rodolfo, A., Volpi, C., Eds.; Edizioni Musei Vaticani: Città del Vaticano, Vatican, 2014; Volume 1, pp. $249-282$. 
6. Ingo, G.M.; Balbi, S.; de Caro, T.; Fragalà, I.; Angelini, E.; Bultrini, G. Combined use of SEM-EDS, OM and XRD for the characterization of corrosion products grown on silver roman coins. Appl. Phys. A Mater. Sci. Process. 2006, 8, 493-497. [CrossRef]

7. Ioele, M.; Jervis, A.V.; Paris, M.; Rissotto, L.; Sodo, A.; Giovagnoli, A.; Poli, T. Presence of Indigo in the Paint Layers of Gilt and Painted Leather Artefacts. In Proceedings of the ICOM Committee for Conservation, Lisbon, Portugal, 19-23 September 2011; pp. 1-9.

8. Tortora, L.; Notaristefani, F.; Ioele, M. ToF-SIMS investigation of gilt and painted leather: Identification of indigo, oil binder and gold varnish. Surf. Interface Anal. 2014, 46, 807-811. [CrossRef]

9. Sodhi, R.N.S. Time-of-flight secondary ion mass spectrometry (TOF-SIMS): Versatility in chemical and imaging surface analysis. Analyst 2004, 129, 483-487. [CrossRef] [PubMed]

10. Ingo, G.M.; Riccucci, C.; Pascucci, M.; Messina, E.; Giuliani, C.; Biocca, P.; Tortora, L.; Fierro, G.; di Carlo, G. Combined use of FE-SEM+EDS, ToF-SIMS, XPS, XRD and OM for the study of ancient gilded artefacts. Appl. Surf. Sci. 2018, 446, 168-176. [CrossRef]

11. Richardin, P.; Mazel, V.; Walter, P.; Laprévote, O.; Brunelle, A. Identification of different copper green pigments in renaissance paintings by Cluster-TOF-SIMS imaging analysis. J. Am. Soc. Mass Spectrom. 2011, 22, 1729-1736. [CrossRef] [PubMed]

12. Sanyova, J.; Cersoy, S.; Richardin, P.; Lapr, O.; Walter, P.; Brunelle, A. Unexpected materials in a rembrandt painting characterized by high spatial resolution Cluster-TOF-SIMS imaging. Anal. Chem. 2011, 83, 753-760. [CrossRef]

13. Noun, M.; van Elslande, E.; Touboul, D.; Glanville, H.; Bucklow, S.; Brunelle, A. High mass and spatial resolution mass spectrometry imaging of Nicolas Poussin painting cross section by cluster TOF-SIMS. J. Mass Spectrom. 2016, 51, 1196-1210. [CrossRef]

14. Vanbellingen, Q.P.; Elie, N.; Eller, M.J.; Della-negra, S.; Touboul, D.; Brunelle, A. Time-of-flight secondary ion mass spectrometry imaging of biological samples with delayed extraction for high mass and high spatial resolutions. Rapid Commun. Mass Spectrom. 2015, 29, 1187-1195. [CrossRef]

15. Atrei, A.; Benetti, F.; Gliozzo, E.; Perra, G.; Marchettini, N. Chemical characterization of protein based binders in painting samples by means of ToF-SIMS: Tests on ancient and model samples. Int. J. Mass Spectrom. 2014, 369, 9-15. [CrossRef]

16. Ingo, G.M.; Guida, G.; Angelini, E.; di Carlo, G.; Mezzi, A.; Padeletti, G. Ancient mercury-based plating methods: Combined use of surface analytical techniques for the study of manufacturing process and degradation phenomena. Acc. Chem. Res. 2013, 46, 2365-2375. [CrossRef] [PubMed]

17. Ridolfi, S.; Tabasso, M.L.; Chaverdi, A.A.; Callieri, P. The finishing technique of the stone monuments of Persepolis: Further studies and new findings through the use of non-destructive analytical techniques. Archaeometry 2019, 61, 272-281. [CrossRef]

18. Available online: https://www.thermofisher.com/order/catalog/product/912A0760 (accessed on 16 July 2019).

19. Levey, B.M. Alum in ancient mesopotamian technology. Univ. Chic. Press J. 1958, 49, 166-169. [CrossRef]

20. Hamman, J.H. Composition and applications of aloe vera leaf gel. Molecules 2008, 13, 1599-1616. [CrossRef] [PubMed]

21. Derrick, M. Fourier transform infrared spectral analysis of natural resins used in furniture finishes. J. Am. Inst. Conserv. 1989, 28, 43-56. [CrossRef]

22. Beltran, V.; Salvadó, N.; Butí, S.; Pradell, T. Ageing of resin from Pinus species assessed by infrared spectroscopy. Anal. Bioanal. Chem. 2016, 408, 4073-4082. [CrossRef] [PubMed]

23. Keune, K.; Boon, J.J. Analytical imaging studies of cross-sections of paintings affected by lead soap aggregate formation. Stud. Conserv. 2014, 52, 161-176. [CrossRef]

24. Shearer, G.L. An Evaluation of Fourier Transform Infrared Spectroscopy for the Characterization of Organic Compunds in Art and Archaeology. Ph.D. Thesis, University College London, London, UK, 1989.

25. Lin-Vien, D.; Colthup, N.B.; Fateley, W.G.; Grasselli, J.G. The Handbook of Infrared and Raman Characteristic Frequencies of Organic Molecules; Academic Press: Boston, MA, USA, 1991. [CrossRef]

26. Rahmaninia, M.; Javid, E.; Varshoei, A. Process variables and the performance of cationic rosin as an internal sizing agent in recycled corrugated container pulp. BioResources 2016, 11, 5333-5342. [CrossRef]

27. Rao, Z.; Dong, K.; Yang, X.; Lin, J.; Cui, X.; Zhou, R.; Deng, Q. Natural amber, copal resin and colophony investigated by UV-VIS, infrared and Raman spectrum. Sci. China Phys. Mech. Astron. 2013, 56, 1598-1602. [CrossRef] 
28. Noble, P. Chemical changes in old master paintings II: Darkening due to increased transparency as a result of metal soap formation. In Proceedings of the ICOM Committee for Conservation, The Hague, The Netherlands, 12-16 September 2005; Volume 1.

29. Cotte, M.; Checroun, E.; de Nolf, W.; Taniguchi, Y.; de Viguerie, L.; Burghammer, M.; Walter, P.; Rivard, C.; Salomé, M.; Janssens, K.; et al. Lead soaps in paintings: Friends or foes? Stud. Conserv. 2017, 62, 2-23. [CrossRef]

30. Centeno, S.A.; Mahon, D. The chemistry of aging in oil paintings: Metal soaps and visual changes. Metrop. Mus. Art Bull. New Ser. 2019, 67, 12-19. Available online: https://www.jstor.org/stable/40588562 (accessed on 24 June 2019).

31. Sodo, A.; Biocca, P.; Municchia, A.C.; Fiorin, E.; Antonietta, M. Raman and time of flight secondary ion mass spectrometry investigation answers specific conservation questions on Bosch painting Saint Wilgefortis Triptych. J. Raman Spectrosc. 2019, 50, 150-160. [CrossRef]

32. Biocca, P.; Santopadre, P.; Sidoti, G.; Sotgiu, G.; Notaristefani, F.; Tortora, L. ToF-SIMS study of gilding technique in the fresco Vela della Castità by Giotto's school. Surf. Interface Anal. 2016, 48, 404-408. [CrossRef]

33. Miller, F.A.; Wilkins, C.H. Infrared spectra and characteristic frequencies of inorganic ions their use in qualitative analysis. Anal. Chem. 1952, 24, 1253-1294. [CrossRef]

34. Brusentsova, T.N.; Peale, R.E.; Maukonen, D.; Harlow, G.E.; Boesenberg, J.S.; Ebel, D. Far infrared spectroscopy of carbonate minerals. Am. Mineral. 2010, 95, 1515-1522. [CrossRef]

35. Kendix, E.L. Transmission and Reflection (ATR) Far-Infrared Spectroscopy Applied in the Analysis of Cultural Heritage Materials. Ph.D. Thesis, Alma Mater Studiorum-Università di Bologna, Bologna, Italy, 2009.

36. Mathey, Y.; Greig, D.R.; Shriver, D.F.; Mathey, Y.; Greig, D.R. Variable-temperature Raman and infrared spectra of the copper acetate dimer $\mathrm{Cu}_{2}\left(\mathrm{O}_{2} \mathrm{CCH}_{3}\right)_{4}\left(\mathrm{H}_{2} \mathrm{O}\right)_{2}$ and its derivatives. Inorg. Chem. 1982, 21, 3409-3413. [CrossRef]

37. Ito, K.; Bernstein, H.J. The vibrational spectra of the formate, acetate, and oxalate ions. Can. J. Chem. 1956, 34, 170-178. [CrossRef]

38. D'Antonio, M.C.; Palacios, D.; Coggiola, L.; Baran, E.J. Vibrational and electronic spectra of synthetic moolooite. Spectrochim. Acta Part A 2007, 68, 424-426. [CrossRef]

39. Colombini, M.P.; Modugno, F.; Fuoco, R.; Tognazzi, A. A GC-MS study on the deterioration of lipidic paint binders. Microchem. J. 2002, 73, 175-185. [CrossRef]

40. Zoppi, A.; Lofrumento, C. Metal oxalates in paints: A Raman investigation on the relative reactivities of different pigments to oxalic acid solutions. Anal. Bioanal. Chem. 2010, 397, 841-849. [CrossRef] [PubMed]

41. Bordignon, F.; Postorino, P.; Dore, P.; Tabasso, M.L. The formation of metal oxalates in the painted layers of a medieval polychrome on stone, as revealed by micro-Raman spectroscopy. Stud. Conserv. 2019, 53, 158-169. [CrossRef]

42. Angelini, E.; Ingo, G.M.; Grassini, S.; Corbellini, S.; de Caro, T.; Riccucci, C.; Plescia, P.; Agostini, S.; Bianco, A. Potentialities of XRF and EIS portable instruments for the characterisation of ancient artefacts. Appl. Phys. A Mater. Sci. Process. 2006, 83, 643-649. [CrossRef]

(C) 2019 by the authors. Licensee MDPI, Basel, Switzerland. This article is an open access article distributed under the terms and conditions of the Creative Commons Attribution (CC BY) license (http://creativecommons.org/licenses/by/4.0/). 